Article

\title{
Design of a Nonlinear Predictive Controller for a Fractional-Order Hydraulic Turbine Governing System with Mechanical Time Delay
}

\author{
Yuqiang Tian ${ }^{1,2}$, Bin Wang ${ }^{1,2, *}$, Diyi Chen ${ }^{1,2, *}$, Shaokun Wang ${ }^{1}$, Peng Chen ${ }^{1}$ and Ying Yang 1 \\ 1 Department of Electrical Engineering, College of Water Resources and Architectural Engineering, Northwest \\ A\&F University, Yangling 712100, China; tyq@nwafu.edu.cn (Y.T.); wsk9001@nwafu.edu.cn (S.W.); \\ chenpeng007@nwafu.edu.cn (P.C.); yangying1995@nwafu.edu.cn (Y.Y.) \\ 2 Key Laboratory of Agricultural Soil and Water Engineering in Arid and Semiarid Areas, \\ Ministry of Education, Northwest A\&F University, Yangling 712100, China \\ * Correspondence: binwang@nwsuaf.edu.cn (B.W.); diyichen@nwsuaf.edu.cn (D.C.)
}

Received: 5 November 2019; Accepted: 8 December 2019; Published: 11 December 2019

\begin{abstract}
A nonlinear predictive control method for a fractional-order hydraulic turbine governing system (HTGS) with a time delay is studied in this paper. First, a fractional-order model of a time-delay hydraulic turbine governing system is presented. Second, the fractional-order hydraulic servo subsystem is transformed into a standard controlled autoregressive moving average (CARMA) model according to the Grünwald-Letnikov (G-L) definition of fractional calculus. Third, based on the delayed Takagi-Sugeno fuzzy model, the fuzzy prediction model of the integer-order part of the HTGS is given. Then, by introducing a fourth-order Runge-Kutta algorithm, the fuzzy prediction model can be easily transformed into the CARMA model. Furthermore, a nonlinear predictive controller is proposed to stabilize the time-delay HTGS. Finally, the experiment results are consistent with the theoretical analysis.
\end{abstract}

Keywords: hydraulic turbine governing system; delayed Takagi-Sugeno fuzzy model; fractional calculus; nonlinear predictive control; time delay; mechanical inertia

\section{Introduction}

Efforts to develop clean energy and to improve the status of clean energy in international energy architecture are urgently needed because of the burning of large amounts of fossil fuels. Water energy as a clean source has been extensively developed in recent years [1-3]. There are ever increasing numbers of high-capacity and high-head hydropower stations. It is particularly important for such giant hydro-turbine units to ensure their safe and stable operation [4-6]. However, there are varying degrees of stability problems in large and medium-sized hydroelectric generator units in production practice both at home and abroad [7-10]. The stability of the hydro-generator sets plays an important role in the stability of the power grid system. Therefore, it is of great significance to control the hydraulic turbine governing system (HTGS) in a high quality way.

Nonlinear modeling and dynamic analysis of hydraulic turbine governing systems has always been a topic of interest, and there has been much research in this area [11-17]. There is a consensus that fractional calculus is superior to integer calculus in describing systems with memory, historical dependence, and viscoelasticity [18-29]. Considering the nonlinear, time-varying and nonminimum phase characteristics of hydraulic turbine governing systems, some scholars have introduced fractional calculus to establish mathematical models of HTGS which are more in line with engineering practice [30-32]. On the basis of accurate modeling, stability control of HTGS has attracted many scholars' attention. However, at present, the control methods of HTGS mainly focus on asymptotic 
stability theory and finite time theory [33-40]. Theoretically, the time required for the asymptotic stability theory to make the system stable is infinite. Although finite-time control can improve the system transition process, including overshoot, stability time, and oscillation times, the control system requires a certain amount of time from signal acquisition and processing to the controller operation, which leads to the time lag of the control. In addition, due to the time-delay effect from the mechanical inertia and multi-stage hydraulic amplifier of the hydraulic pressure system, the control of the HTGS will undoubtedly become more difficult.

Predictive control plays an active role in prediction and online optimization and is fundamentally different from traditional control methods, making it an area of significant research activity [41-43]. Also, predictive control has natural advantages in dealing with time delays [44]. Currently, predictive control theory for linear systems is relatively mature but the theoretical research of nonlinear predictive control is still in its infancy. Can fuzzy techniques and generalized predictive control (GPC) be combined for the control of the fractional-order nonlinear time-delay HTGS? If possible, how could the fuzzy model be matched with GPC, and what are the detailed controller forms and specific stability theorems? These questions have not been considered.

Inspired by the above discussion, there are several advantages which make our study attractive. First, considering the mechanical inertia of a hydraulic servo system and the strong historical dependence of relay parts, a fractional-order nonlinear HTGS with a time delay is presented. Second, the Grünwald-Letnikov (G-L) definition is used to deal with the fractional order model of HTGS with time delay, and the fractional hydraulic servo system is transformed into the standard CARMA model, which provides a model basis for the control of the system. Third, the time-delay Takagi-Sugeno (T-S) fuzzy theory is applied to get the fuzzy predictive model of the integer-order part of the time-delay HTGS. Furthermore, through a fourth-order Runge-Kutta algorithm, we can transform the fuzzy predictive model into the CARMA model. Then, based on the obtained CARMA model and the generalized predictive control (GPC) theory, a nonlinear fuzzy generalized predictive controller is designed for the fractional-order time-delay HTGS. Finally, the effectiveness and superiority of the proposed scheme are verified by numerical simulation.

The organization of the remainder of this paper is follows: In Section 2, a fractional-order HTGS with time delay is given. Section 3 presents the model transformation and controller design. Numerical experiments are performed in Section 4. Finally, conclusions are provided in Section 5.

\section{System Description}

The hydraulic turbine governing system is described as in references [30,31,45]:

$$
\left\{\begin{array}{l}
\dot{\delta}=\omega_{0} \omega \\
\dot{\omega}=\frac{1}{T_{a b}}\left[m_{t}-D \omega-\frac{E_{q}^{\prime} V_{s}}{x_{d \Sigma}^{\prime}} \sin \delta-\frac{V_{s}^{2}}{2} \frac{x_{d \Sigma}^{\prime}-x_{q \Sigma}}{x_{d \Sigma}^{\prime} x_{q \Sigma}} \sin 2 \delta\right] \\
\dot{m}_{t}=\frac{1}{e_{q h} T_{w w}}\left[-m_{t}+e_{y} \mu-\frac{e e_{y} T_{w}}{T_{y}}(u-\mu)\right] \\
\dot{\mu}=\frac{1}{T_{y}}(u-\mu)
\end{array}\right.
$$

where $\delta, \omega, m_{t}, \mu$ are the generator rotor angle deviation, the rotational speed relative deviation of the generator, the hydro-turbine output incremental torque deviation, and the incremental deviation of the guide vane opening, respectively; $T_{a b}, T_{\mathrm{w}}$ and $T_{y}$ are the sum of the inertia time constants of the rotating part of the unit and load, the inertia time constant of the pressure diversion system, and the reaction time constant of the relay, respectively; $D$ is the damping coefficient of generator speed deviation; $E_{q}^{\prime}$ is the generator $q$-axis transient electromotive force; $x_{d \Sigma}^{\prime}$ and $x_{q \Sigma}$ are generator $d$-axis transient reactance and $q$-axis synchronous reactance, respectively; $V_{s}$ is infinite bus voltage; $e_{q h}$ and $e_{q y}$ are the head transfer coefficient and the relay stroke transfer coefficient of the flow, respectively; $e_{y}$ and $e_{h}$ is the relay stroke transfer coefficient and the head transfer coefficient of hydro-turbine torque, respectively; $e=\frac{e_{q y} e_{h}}{e_{y}}-e_{q h}$; Here, the control input is not taken into account, i.e., $u=0$. 
The mechanical inertia of the hydraulic servo system and the displacement response of the piston of the servo motor make the system show a lag characteristic. At the same time, because the mechanical material has a metal memory property and the water flow through the guide vane has a certain viscoelasticity, the system presents a fractional property in the relay. Therefore, the fractional-order hydraulic servo system with a time delay is employed [31]:

$$
D^{\alpha} \mu=-\frac{1}{T_{y}} \mu(t-\tau)
$$

where $\tau=k_{n} h$ is the time delay, $k_{n}$ is the delay steps and $h$ is the sampling interval.

According to Equations (1) and (2), the fractional-order nonlinear HTGS with a time delay is represented as:

$$
\left\{\begin{array}{l}
\dot{\delta}=\omega_{0} \omega \\
\dot{\omega}=\frac{1}{T_{a b}}\left[m_{t}-D \omega-\frac{E_{q}^{\prime} V_{s}}{x_{d \Sigma}^{\prime}} \sin \delta-\frac{V_{s}^{2}}{2} \frac{x_{d \Sigma}^{\prime}-x_{q \Sigma}}{x_{d \Sigma}^{\prime} x_{q \Sigma}} \sin 2 \delta\right] \\
\dot{m}_{t}=\frac{1}{e_{q h} T_{w w}}\left[-m_{t}+e_{y} \mu(t-\tau)+\frac{e e_{y} T_{w}}{T_{y}} \mu(t-\tau)\right] \\
D^{\alpha} \mu=-\frac{1}{T_{y}} \mu(t-\tau)
\end{array}\right.
$$

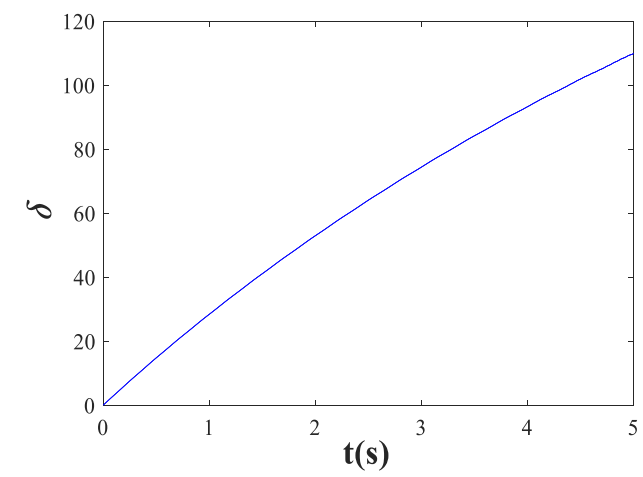

(a) $\delta(t)-t$

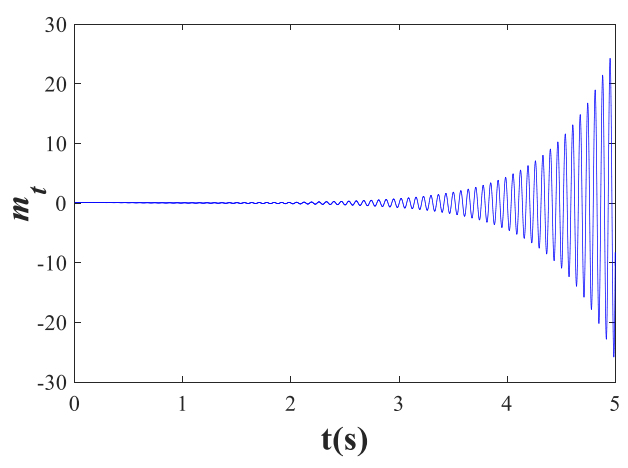

(c) $m_{t}(t)-t$

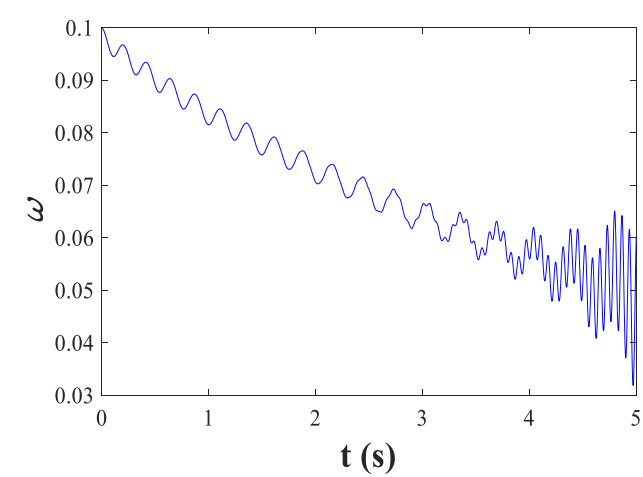

(b) $\omega(t)-t$

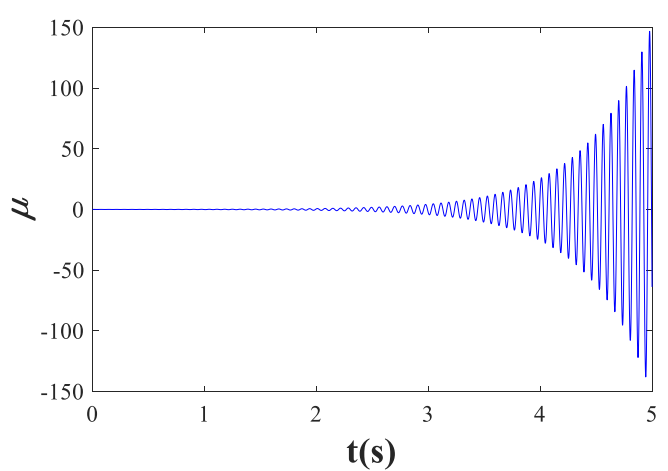

(d) $\mu(t)-t$

Figure 1. The time domain of the pre-controlled stated variables.

In Equation (3), the parameters are set as follows: $\omega_{0}=314 \mathrm{rad} / \mathrm{s}, T_{a b}=9.0 \mathrm{~s}, D=2.0, E_{q}^{\prime}=1.35$, $T_{w}=0.8 \mathrm{~s}, T_{y}=0.1 \mathrm{~s}, x_{d \Sigma}^{\prime}=1.25, x_{q \Sigma}=1.474, V_{s}=1.0, e=0.7, e_{q h}=0.5, e_{y}=1.0, \alpha=0.5, k_{n}=50$, $h=0.001 \mathrm{~s}$.

To facilitate the mathematical analysis, we use $x=\left[x_{1}, x_{2}, x_{3}, x_{4}\right]$ and replace $\left[\delta, \omega, m_{t}, \mu\right]$. The time domain of the HTGS (3) in starting operation is shown in Figure 1. It is clear that the fractional-order time-delay HTGS (3) is experiencing unstable and irregular vibrations with an initial value $\left[\delta, \omega, m_{t}, \mu\right]=$ $[0.1,0.1,0.1,0.1]$, which needs to be controlled. 


\section{Nonlinear Predictive Control Design}

\subsection{Fractional-Order Prediction Model}

The fractional differential equation can be used to describe the fractional-order model:

$$
a_{i} D_{t}^{\beta_{n}} y(t)+a_{i-1} D_{t}^{\beta_{n-1}} y(t)+\cdots+a_{1} D_{t}^{\beta_{1}} y(t)+a_{0} D_{t}^{\beta_{0}} y(t)=u(t)
$$

where $a_{i}(i=1,2,3 \cdots n)$ is an arbitrary real coefficient, $y(t)$ is a state variable, $D^{\beta_{n}}$ is the $\beta_{n}$-order differential of $y(t)$, and $u(t)$ is the input.

When the initial value of $y(t)$ is zero, the transfer function of the fractional-order differential equation is:

$$
G(s)=\frac{1}{a_{n} s^{\beta_{n}}+a_{n-1} s^{\beta_{n-1}}+\cdots+a_{1} s^{\beta_{1}}+a_{0} s^{\beta_{0}}}
$$

On the basis of G-L definition, the $\beta_{n}$-order differential of $y(t)$ can be given as follows:

$$
\begin{aligned}
{ }_{a} D_{t}^{\beta_{n}} y(t) & =\frac{1}{h^{\beta n}} \sum_{j=0}^{[(t-a) / h]} \omega_{j}^{\left(\beta_{n}\right)} y(t-j h) \\
& =\frac{1}{h^{\beta n}}\left[y(t)+\sum_{j=1}^{[(t-a) / h]} \omega_{j}^{\left(\beta_{n}\right)} y(t-j h)\right] .
\end{aligned}
$$

where $h$ is the sampling interval, ${ }_{a} D_{t}^{\beta_{n}}$ is G-L differential operator, and $\omega_{j}^{\left(\beta_{n}\right)}$ can be obtained from the recursive formula:

$$
\omega_{0}^{\left(\beta_{n}\right)}=1, \omega_{j}^{\left(\beta_{n}\right)}=\left(1-\frac{\beta_{n}+1}{j}\right) \omega_{j-1}^{\left(\beta_{n}\right)}, j=1,2,3 \cdots+\infty .
$$

For general control objects, the transfer function model can be identified as fractional order plus pure delay. And it can be expressed as follows:

$$
G(s)=\frac{y(s)}{u(s)}=\frac{K}{T s^{\beta}+1} e^{-m s}
$$

where $\beta \in(0,1)$ is the fractional order, $m$ is the time-delay constant, $T$ is the time constant, and $K$ is arbitrary real coefficient.

Through a Laplace inverse transformation, one can obtain:

$$
T_{a} D_{t}^{\beta} y(t)+y(t)=K u(t-m)
$$

The discretization function is obtained:

$$
{ }_{a} D_{t}^{\beta} y(t) \approx \frac{1}{h^{\beta}} \sum_{j=0}^{[(t-a) / h]} \omega_{j}^{(\beta)} y(t-j h) .
$$

The current time is $t=k h$ and is denoted by the time point $k$, the lag time is $a=k_{n} h$ and is denoted by the time point $k-k_{n}$. Then, (11) can be transformed as follows:

$$
\begin{aligned}
{ }_{a} D_{t}^{\beta} y(t) & \approx \frac{1}{h^{\beta}} \sum_{j=0}^{\left[\left(k h-\left(k-k_{n}\right) h\right) / h\right]} \omega_{j}^{(\beta)} y(k h-j h) \\
& \approx \frac{1}{h^{\beta}} \sum_{j=0}^{k_{n}} \omega_{j}^{(\beta)} y(k h-j h) \\
& \approx \frac{1}{h^{\beta}}\left(\omega_{0}^{(\beta)} y(k h)+\omega_{1}^{(\beta)} y((k-1) h)+\cdots+\omega_{\tau}^{(\beta)} y\left(\left(k-k_{n}\right) h\right)\right) .
\end{aligned}
$$


From Equations (9) and (11), one can obtain:

$$
T \frac{1}{h^{\beta}}\left(\omega_{0}^{(\beta)} y(k)+\omega_{1}^{(\beta)} y(k-1)+\cdots+\omega_{\tau}^{(\beta)} y\left(k-k_{n}\right)\right)+y(k)=K u(k-m)
$$

Substituting Equation (7) into Equation (12), we have:

$$
\begin{aligned}
y(k)= & \frac{T \beta}{T+h^{\beta}} y(k-1)+\frac{T(1-\beta) \beta}{2 !\left(T+h^{\beta}\right)} y(k-2)+\frac{T(2-\beta)(1-\beta) \beta}{3 !\left(T+h^{\beta}\right)} y(k-3)+\cdots+ \\
& \frac{T\left(k_{n}-1-\beta\right) \cdots(2-\beta)(1-\beta) \beta}{k_{n} !\left(T+h^{\beta}\right)} y\left(k-k_{n}\right)+\frac{K h^{\beta}}{T+h^{\beta}} u(k-m)
\end{aligned}
$$

Based on Equations (9)-(13), the fractional-order $D^{\alpha} \mu=-\frac{1}{T_{y}} \mu(t-\tau)$ in HTGS (3) can be expressed as

$$
\begin{aligned}
\mu(k)= & \frac{T_{y} \alpha}{h^{\alpha}} \mu(k-1)+\frac{T_{y}(1-\alpha) \alpha}{2 !\left(h^{\alpha}\right)} \mu(k-2)+\frac{T_{y}(2-\alpha)(1-\alpha) \alpha}{3 !\left(h^{\alpha}\right)} \mu(k-3)+\cdots+ \\
& \left(\frac{T_{y}\left(k_{n}-1-\alpha\right) \cdots(2-\alpha)(1-\alpha) \alpha}{k_{n} !\left(h^{\alpha}\right)}-\frac{h^{\alpha}}{T_{y}}\right) \mu\left(k-k_{n}\right)
\end{aligned}
$$

\subsection{Integer-Order Prediction Model}

The following is the delayed Takagi-Sugeno (T-S) fuzzy model [46-48]:

$$
\begin{aligned}
R^{i}: & \text { if } z_{1}(t) \text { is } M_{i 1} \text { and } \cdots \text { and } z_{p}(t) \text { is } M_{i p} \\
& \text { then }: E \dot{y}(t)=A_{i z} y(t)+A_{z d i} y(t-\tau)
\end{aligned}
$$

where $R^{i}$ is the $i$-th rule of the T-S fuzzy model, $z(t)=\left[z_{1}(t), \cdots, z_{p}(t)\right]$ are the premise variables, $M_{i j}(j=1,2 \cdots p)$ is the fuzzy set, $y(t) \in R^{n}$ are the state variables of the system, $E=\left[\begin{array}{ll}I & 0 \\ 0 & 0\end{array}\right], I \in$ $R^{(n-1) \times(n-1)}, I$ is identity matrix, $A_{i z} \in R^{n \times n}$ and $A_{z d i}{ }^{n \times n}$ are normal real matrices with proper dimensions.

The membership function is selected as shown in Figure 2 and is presented as:

$$
\begin{gathered}
M_{p}=\left\{\begin{array}{cc}
0 & y_{i}<-d \\
\frac{y_{i}+d}{2 d} & -d \leq y_{i} \leq d, \\
1 & y_{i}>d
\end{array}\right. \\
M_{n}=\left\{\begin{array}{cc}
1 & y_{i}<-d \\
\frac{-y_{i}+d}{2 d} & -d \leq y_{i} \leq d . \\
0 & y_{i}>d
\end{array}\right.
\end{gathered}
$$

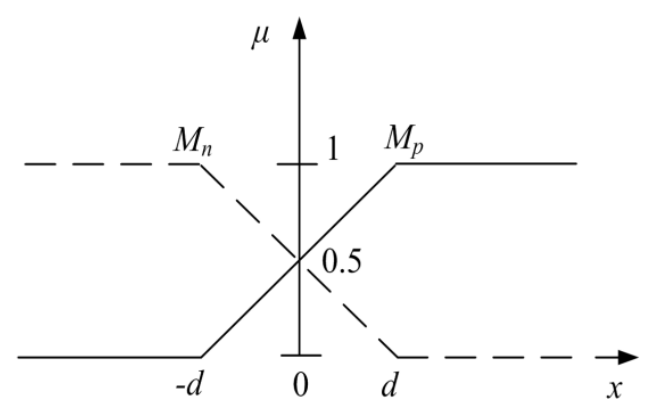

Figure 2. The graphical definition of the membership function.

Then, the delayed T-S fuzzy model is obtained as:

$$
\dot{y}(t)=A_{1 z}(t) y(t)+A_{\tau z}(t) y(t-\tau)
$$


where $A_{1 z}=\sum_{i=1}^{r} h_{i}(z(t)) A_{i i z}, A_{\tau z}=\sum_{i=1}^{r} h_{i}(z(t)) A_{\tau i z}, h_{i}(z(t))=\frac{\omega_{i}(z(t))}{\sum_{i=1}^{r} \omega_{i}(z(t))}, \omega_{i}(z(t))=\prod_{j=1}^{n} M_{i j}\left(z_{j}(t)\right)$, $h_{i}(z(t)) \geq 0, i=1, \cdots, r, \sum_{i=1}^{r} h_{i}(z(t))=1$.

The transformation from the delayed T-S fuzzy model Equation (17) into the CARMA model is straightforward by using the forth-order Runge-Kutta algorithm, which can address a time delay, is given as:

$$
\begin{aligned}
& y_{k+1}=y_{k}+\frac{h}{6}\left(K_{1}+2 K_{2}+2 K_{3}+K_{4}\right) \\
& \left\{\begin{array}{l}
K_{1}=f\left(t_{k}, y_{k}, y\left(t_{k}-k_{n}\right)\right) \\
K_{2}=f\left(t_{k}+\frac{h}{2}, y_{k}+h \frac{K_{1}}{2}, y\left(t_{k}+\frac{h K_{1}}{2}-k_{n}\right)\right) \\
K_{3}=f\left(t_{k}+\frac{h}{2}, y_{k}+h \frac{K_{2}}{2}, y\left(t_{k}+\frac{h K_{2}}{2}-k_{n}\right)\right. \\
K_{4}=f\left(t_{k}+h, y_{k}+h K_{3}, y\left(t_{k}+\frac{h K_{3}}{2}-k_{n}\right)\right)
\end{array}\right.
\end{aligned}
$$

The delayed T-S fuzzy model Equation (17) can be described as:

$$
\left\{\begin{array}{c}
\dot{Y}=A Y+A_{\tau} Y_{\tau} \\
Y_{0}=\left[y_{1,0}, y_{2,0}, y_{3,0}, \cdots, y_{n, 0}\right]^{T}
\end{array}\right.
$$

According to Equation (18), we have: $Y_{n+1}=Y_{n}+\frac{h}{6}\left(K_{1}+2 K_{2}+2 K_{3}+K_{4}\right)$,

$\left\{\begin{array}{c}K_{1}=A Y+A_{\tau} Y_{\tau} \\ K_{2}=A\left(Y+\frac{h}{2} K_{1}\right)+A_{\tau}\left(Y_{\tau}+\frac{h}{2} K_{1}\right) \\ K_{3}=A\left(Y+\frac{h}{2} K_{2}\right)+A_{\tau}\left(Y_{\tau}+\frac{h}{2} K_{2}\right) \\ K_{4}=A\left(Y+h K_{3}\right)+A_{\tau}\left(Y_{\tau}+\frac{h}{2} K_{3}\right) \\ \text { Therefore, one can obtain: }\end{array}\right.$

$$
\begin{aligned}
Y_{\mathrm{n}+1} & =Y_{n}+\frac{h}{6}\left(K_{1}+2 K_{2}+2 K_{3}+K_{4}\right) \\
& =Y_{n}+\left(\frac{h A_{1 z}\left(12 h\left(A_{1 z}+A_{\tau z}\right)+4 h^{2}\left(A_{1 z}+A_{\tau z}\right)^{2}+h^{3}\left(A_{1 z}+A_{\tau z}\right)^{3}+24\right)}{24}\right) Y_{n} \\
& +\left(\frac{h A_{\tau z}\left(12 h\left(A_{1 z}+A_{\tau z}\right)+4 h^{2}\left(A_{1 z}+A_{\tau z}\right)^{2}+h^{3}\left(A_{1 z}+A_{\tau z}\right)^{3}+24\right)}{24}\right) Y_{\tau}
\end{aligned}
$$

By T-S fuzzy theory, the fuzzy model of integer order variable $\dot{x}_{z}=E \dot{x}$ in HTGS (3) can be obtained as follows:

$$
\dot{x}_{z}(t)=A_{z} x(t)+A_{d z} x(t-\tau)
$$

where $A_{z}=\sum_{i=1}^{r} h_{i}(z(t)) A_{z i}$ and $A_{d z}=\sum_{i=1}^{r} h_{i}(z(t)) A_{d z i}$ are the coefficient matrices of the model. In Equation (21), only the integer order model in system (3) is considered, so the influence of fractional order should be ignored. That is, the last row of the coefficient matrix $A_{d z}$ should be set to 0 .

The fourth-order Runge-Kutta algorithm is used to discretized system Equation (21), and the discrete model can be described as:

$$
\begin{gathered}
x_{z}(k+1)=x_{z}(k)+\left(\frac{h A_{z}\left(12 h\left(A_{z}+A_{d z}\right)+4 h^{2}\left(A_{z}+A_{d z}\right)^{2}+h^{3}\left(A_{z}+A_{d z}\right)^{3}+24\right)}{24}\right) x_{z}(k) \\
+\left(\frac{h A_{\tau}\left(12 h\left(A_{z}+A_{d z}\right)+4 h^{2}\left(A_{z}+A_{d z}\right)^{2}+h^{3}\left(A_{z}+A_{d z}\right)^{3}+24\right)}{24}\right) x_{z}\left(k-k_{n}\right)
\end{gathered}
$$

\subsection{Controller Design}

The following presents the CARMA model:

$$
A\left(z^{-1}\right) Y(k)=z^{-d} B\left(z^{-1}\right) U(k)+C\left(z^{-1}\right) \xi(k)
$$


where the state vector is $Y(k)=\left[y_{1}(k), y_{2}(k), \cdots, y_{n}(k)\right]^{T}$, the control input is $U(k)=\left[u_{1}(k), u_{2}(k), \cdots, u_{n}(k)\right]^{T}$, the white noise is $\xi(k)=\left[\xi_{1}(k), \xi_{2}(k), \cdots, \xi_{n}(k)\right]^{T}$, and

$$
\left\{\begin{array}{l}
A\left(z^{-1}\right)=I+A_{1} z^{-1}+A_{2} z^{-2}+\cdots+A_{n_{a}} z^{-n_{a}} \\
B\left(z^{-1}\right)=B_{1,0}+B_{1,1} z^{-1}+B_{1,2} z^{-2}+\cdots+B_{1, n_{b}} z^{-n_{b}}, B_{1,0} \neq 0 . \\
C\left(z^{-1}\right)=C_{0}+C_{1} z^{-1}+C_{2} z^{-2}+\cdots+C_{n_{c}} z^{-n_{c}}, C_{0}=I
\end{array}\right.
$$

where $A_{1}, A_{2}, \cdots, A_{n_{a}}, B_{1,0}, B_{1,1}, \cdots, B_{1, n_{b}}, C_{1}, C_{2}, \cdots, C_{n_{c}}$ are coefficient matrices.

Combined with Equations (14) and (22), external noise and controller are added to the system. When the system just has $A_{1}, A_{\tau}, B_{1,0}, C_{0}$ and $d=1$, the CARMA model of the system can be expressed as

$$
x(k+1)=-A_{1} x(k)-A_{\tau} x\left(k-k_{n}\right)+B_{1,0} U(k)+C_{0} \xi(k)
$$

where $A_{1}=A_{z}, A_{\tau}=A_{d z}+A_{f}, A_{f}$ is fractional time-delay coefficient matrix, $A_{f}=$ $\left[\begin{array}{cccc}0 & 0 & 0 & 0 \\ 0 & 0 & 0 & 0 \\ 0 & 0 & 0 & 0 \\ 0 & 0 & 0 & \frac{T_{y}\left(k_{n}-1-\alpha\right) \cdots(2-\alpha)(1-\alpha) \alpha}{k_{n} !\left(h^{\alpha}\right)}-\frac{h^{\alpha}}{T_{y}}\end{array}\right]$.

Theorem 1. Taking the CARMA model Equation (24) of fractional-order HTGS (3) into consideration, the future output prediction model could be given as:

$$
X=X_{m}+G \Delta U
$$

Here, $X$ is the prediction output; $X_{m}$ is the corresponding output in the prediction time domain, which is completely determined by the past control input and output; $G$ is the control coefficient matrix, and $\Delta U$ is the control increment vector in the time domain.

$$
X=\left[\begin{array}{c}
x(k+1 \mid k) \\
x(k+2 \mid k) \\
\vdots \\
x(k+N \mid k)
\end{array}\right], X_{m}=\left[\begin{array}{c}
x_{m}(k+1) \\
x_{m}(k+2) \\
\vdots \\
x_{m}(k+N)
\end{array}\right]
$$

$$
\begin{gathered}
\left\{\begin{array}{l}
x_{m}(k)=x(k) \\
x_{m}(k+j)=-A_{1} x_{m}(k+j-1)-A_{\tau} x_{m}\left(k+j-k_{n}\right)+B_{1,0} U(k+j-1 \mid k)+C_{0} \xi(k+j-1 \mid k), j=1,2, \cdots, N
\end{array}\right. \\
U(k+j \mid k)=\left\{\begin{array}{c}
U(k-1), j \geq 0 \\
U(k+j), j<0
\end{array} .\right. \\
\xi(k+j \mid k)=\left\{\begin{array}{ccc}
0, j>0 \\
\xi(k+j), j \leq 0
\end{array} .\right. \\
G=\left[\begin{array}{cccc}
B_{1,0} & 0 & \cdots & 0 \\
B_{2,0} & B_{1,0} & \cdots & 0 \\
\vdots & \vdots & \ddots & \vdots \\
B_{N, 0} & B_{N-1,0} & \cdots & B_{1,0}
\end{array}\right]
\end{gathered}
$$

$N$ is the prediction length.

$$
B_{j, 0}=\left\{\begin{array}{l}
-A_{1} B_{j-1,0}, j<k_{n} \\
-A_{1} B_{j-1,0}-A_{\tau} B_{j-k_{n}, 0}, j \geq k_{n}
\end{array}, j=2,3, \cdots, N .\right.
$$




$$
\Delta U=\left[\begin{array}{c}
\Delta U(k) \\
\Delta U(k+1) \\
\vdots \\
\Delta U(k+N-1)
\end{array}\right], \Delta U(k+i)=U(k+i)-U(k-1)
$$

Theorem 2. Considering the CARMA model (25) of a fractional-order HTGS (3), the system will converge to the reference trajectories $Y_{r}$ under the control law (26).

$$
\Delta U=\left(G^{\mathrm{T}} G\right)^{-1} G\left(Y_{r}-X_{m}\right), U(k)=U(k-1)+\Delta U(k)
$$

Proof of Theorem 1. Step 1: Prove the first term.

$$
\begin{aligned}
x^{*}(k+1 \mid k) & =-A_{1} x(k)-A_{\tau} x\left(k-k_{n}\right)+B_{1,0} U(k) \\
& =-A_{1} x_{m}(k)-A_{\tau} x_{m}\left(k-k_{n}\right)+B_{1,0} U(k) \\
& =-A_{1} x_{m}(k)-A_{\tau} x_{m}\left(k-k_{n}\right)+B_{1,0} U(k-1)+B_{1,0} U(k)-B_{1,0} U(k-1) \\
& =-A_{1} x_{m}(k)-A_{\tau} x_{m}\left(k-k_{n}\right)+B_{1,0} U(k \mid k)+B_{1,0} U(k)-B_{1,0} U(k-1) \\
& =-A_{1} x_{m}(k)-A_{\tau} x_{m}\left(k-k_{n}\right)+B_{1,0} U(k \mid k)+ \\
& C_{0} \xi(k+1 \mid k)+B_{1,0} U(k)-B_{1,0} U(k-1) \\
& =x_{m}(k+1)+B_{1,0} U(k)-B_{1,0} U(k-1) \\
& =x_{m}(k+1)+B_{1,0} \Delta U(k)
\end{aligned}
$$

The first term fulfills Equation (25).

Step 2: Prove the common term.

Suppose $x(k+j \mid k)=x_{m}(k+j)+\sum_{i=1}^{j} B_{i, 0} \Delta U(k+j-i)$ is right, then,

$$
\begin{aligned}
x & (k+j+1 \mid k)=-A_{1} x^{*}(k+j \mid k)-A_{\tau} x^{*}\left(k+j-k_{n} \mid k\right)+B_{1,0} U(k+j) \\
= & -A_{1}\left[x_{m}(k+j)+\sum_{i=1}^{j} B_{i, 0} \Delta U(k+j-i)\right]-A_{\tau}\left[x_{m}\left(k+j-k_{n}\right)+\sum_{i=1}^{j-k_{n}} B_{i, 0} \Delta U(k+j-i)\right] \\
& +B_{1,0} U(k+j) \\
= & -A_{1} x_{m}(k+j)-\sum_{i=1}^{j} A_{1} B_{i, 0} \Delta U(k+j-i)-A_{\tau} x_{m}\left(k+j-k_{n}\right)-\sum_{i=1}^{j-k_{n}} A_{\tau} B_{i, 0} \Delta U(k+j-i) \\
& +B_{1,0} U(k+j) \\
= & -A_{1} x_{m}(k+j)-A_{\tau} x_{m}\left(k+j-k_{n}\right)-\sum_{i=1}^{j} A_{1} B_{i, 0} \Delta U(k+j-i) \\
& j-k_{n} \\
& -\sum_{i=1} A_{\tau} B_{i, 0} \Delta U(k+j-i)+B_{1,0} U(k+j) \\
= & -A_{1} x_{m}(k+j)-A_{\tau} x_{m}\left(k+j-k_{n}\right)+B_{1,0} U(k-1)+ \\
& B_{1,0} \Delta U(k+j)-\sum_{i=1}^{j} A_{1} B_{i, 0} \Delta U(k+j-i)-\sum_{i=1}^{j-k_{n}} A_{\tau} B_{i, 0} \Delta U(k+j-i) \\
= & x_{m}(k+j+1)-\sum_{i=1}^{j} A_{1} B_{i, 0} \Delta U(k+j-i)-\sum_{i=1}^{j-k_{n}} A_{\tau} B_{i, 0} \Delta U(k+j-i)+B_{1,0} \Delta U(k+j) \\
= & x_{m}(k+j+1)-\left(\sum_{i=1}^{j-k_{n}} A_{\tau} B_{i, 0}+\sum_{i=1}^{j} A_{1} B_{i, 0}\right) \Delta U(k+j-i)+B_{1,0} \Delta U(k+j) \\
= & x_{m}(k+j+1)+\sum_{i=1}^{j+1} B_{i, 0} \Delta U(k+j-i)
\end{aligned}
$$

Theorem 1 is proved. 
Proof Theorem 2. To make the output smoothly change over to the set value at a certain response speed, the reference trajectory is often taken as a first-order hysteresis model. The reference trajectory is given below:

$$
Y_{r}=\left[y_{r}^{T}(k), y_{r}^{T}(k+1) \ldots y_{r}^{T}(k+N)\right]^{T} .
$$

where

$$
y_{r}(k)=x_{m}(k), y_{r}(k+i)=\kappa y_{r}(k+i-1)+(1-\kappa) w(k), i=1,2, \ldots, N .
$$

where $\kappa$ is the softness factor matrix, and $w(k)$ is the desired output matrix.

The system objective function is selected as:

$$
J=\mathrm{E}\left\{\left(X-Y_{r}\right)^{\mathrm{T}}\left(X-Y_{r}\right)\right\} .
$$

Then, $\frac{d J}{d \Delta U}=G^{\mathrm{T}} X_{m}+G^{\mathrm{T}} X_{m}+G^{\mathrm{T}} G \Delta U+\left(G^{\mathrm{T}} G\right)^{\mathrm{T}} \Delta U-G^{\mathrm{T}} Y_{r}-G^{\mathrm{T}} Y_{r}=2\left(G^{\mathrm{T}} X_{m}-G^{\mathrm{T}} Y_{r}+G^{\mathrm{T}} G \Delta U\right)$ Let $\frac{d J}{d \Delta U}=0$, there is $\Delta U=\left(G^{\mathrm{T}} G\right)^{-1} G^{\mathrm{T}}\left(Y_{r}-X_{m}\right)$.

According to Equations (25) and (26), one obtains,

$X=X_{m}+G\left(G^{\mathrm{T}} G\right)^{-1} G^{\mathrm{T}}\left(Y_{r}-X_{m}\right)+C \xi$

$=X_{m}+G G^{-1}\left(G^{\mathrm{T}}\right)^{-1} G^{\mathrm{T}}\left(Y_{r}-X_{m}\right)+C \xi$

$=X_{m}+Y_{r}-X_{m}+C \xi$

$=Y_{r}+C \xi$

$y_{r}(k)=x_{m}(k)$,

$y_{r}(k+i)=\kappa y_{r}(k+i-1)+(1-\kappa) w(k), i=1,2, \ldots N$

Therefore,

$y_{r}(k+n)=\kappa^{n+1} y_{r}(k)+\frac{(1-\kappa) R-\kappa^{n+1}(1-\kappa) R}{(1-\kappa)}$

$\lim _{n \rightarrow \infty} y_{r}(k+n)=R$

$\lim _{n \rightarrow \infty} x(k+n)=\lim _{n \rightarrow \infty} y_{r}(k+n)=R$

This completes the proof.

\section{Numerical Experiments}

Consider the system motion within a certain ranger and select $\omega \in[-d, d], d=2$. For the HTGS (3), according to the delayed T-S fuzzy model (15), the following fuzzy rules can be established.

$R^{1}$ : IF $\delta$ is $M_{1}\left(x_{1}(t)\right)$ (near 0$)$, then $\dot{x}_{z}(t)=A_{z 1} x_{z}(t)+A_{d z 1} x_{z}(t-\tau)$;

$R^{2}$ : IF $\delta$ is $M_{2}\left(x_{1}(t)\right)($ near $\pm d)$, then $\dot{x}_{z}(t)=A_{z 2} x_{z}(t)+A_{d z 2} x_{z}(t-\tau)$.

The membership function can be expressed as: $M_{1}\left(x_{1}(t)\right)=\frac{1}{2}\left(1+\frac{x_{1}(t)}{d}\right), M_{2}\left(x_{1}(t)\right)=\frac{1}{2}\left(1-\frac{x_{1}(t)}{d}\right)$.

The coefficient matrix of the integer-order nontime-delay term is given as:

$$
A_{z 1}=\left[\begin{array}{cccc}
0 & 314 & 0 & 0 \\
-0.06905 & -\frac{2}{9} & \frac{1}{9} & 0 \\
0 & 0 & -\frac{5}{2} & 0 \\
0 & 0 & 0 & 0
\end{array}\right], A_{z 2}=\left[\begin{array}{cccc}
0 & 314 & 0 & 0 \\
-0.06326 & -\frac{2}{9} & \frac{1}{9} & 0 \\
0 & 0 & -\frac{5}{2} & 0 \\
0 & 0 & 0 & 0
\end{array}\right]
$$

The coefficient matrix of the integer-order time-delay term is presented as:

$$
A_{d z 1}=\left[\begin{array}{cccc}
0 & 0 & 0 & 0 \\
0 & 0 & 0 & 0 \\
0 & 0 & 0 & \frac{33}{5} \\
0 & 0 & 0 & 0
\end{array}\right], A_{d z 2}=\left[\begin{array}{cccc}
0 & 0 & 0 & 0 \\
0 & 0 & 0 & 0 \\
0 & 0 & 0 & \frac{33}{5} \\
0 & 0 & 0 & 0
\end{array}\right] .
$$


Then, based on Equation (21), the integer-order T-S fuzzy model of HTGS (3) can be rewritten as:

$$
\dot{x}_{z}(t)=\sum_{i=1}^{2} h_{i}(z(t))\left(A_{z i i} x(t)+A_{d i z} x(t-\tau)\right)
$$

Based on Equation (22), the discrete model of the delayed T-S fuzzy model Equation (28) is obtained as:

$$
x_{z}(k+1)=-A_{z} x_{z}(k)-A_{d z} x_{z}\left(k-k_{n}\right)
$$

According to the fractional-order model transformation Equation (24), the fractional time-delay coefficient matrix of HTGS (3) can be obtained as:

$$
A_{f}=\left[\begin{array}{cccc}
0 & 0 & 0 & 0 \\
0 & 0 & 0 & 0 \\
0 & 0 & 0 & 0 \\
0 & 0 & 0 & 0.3154
\end{array}\right] .
$$

Based on Equation (24), the overall CARMA model of fractional-order time-delay HTGS (3) can be obtained from Equations (29) and (30)

$$
x(k+1)=-A_{1} x(k)-A_{\tau} x\left(k-k_{n}\right)+B u(k)
$$

$$
\begin{aligned}
& A_{1}=\left[\begin{array}{cccc}
1.314 & 0.314 & 0.314 & 0.314 \\
1.4244 \times 10^{-5} & 1 & 1.4179 \times 10^{-5} & 1.4421 \times 10^{-5} \\
-0.0025 & -0.0025 & 0.9975 & -0.0025 \\
0 & 0 & 0 & 0
\end{array}\right] \\
& A_{\tau}=\left[\begin{array}{cccc}
0 & 0 & 0 & 0 \\
0 & 0 & 0 & 0 \\
0.0066 & 0.0066 & 0.0066 & 0.0066 \\
0 & 0 & 0 & 3.154
\end{array}\right], B \text { is the fourth-order unit matrix. }
\end{aligned}
$$

\subsection{Case 1: Model Match}

When the unit operates under rated conditions, the transfer coefficients of the hydraulic turbine model are shown in Section 2. The power angle of the hydro-generator unit should be equal to the power grid power angle, i.e., $\delta=0$; the speed should be maintained at the rated speed, i.e., $\omega=0$; the moment of hydraulic turbine should be kept constant to ensure the stability of the turbine speed, i.e., $m_{t}=0$; the opening of the guide vane of the turbine is the rated opening, i.e., $y=0$. Therefore, the expected output value of HTGS (3) should be $w=[0 ; 0 ; 0 ; 0]$. In the experiment, the predicted time domain is $0.06 \mathrm{~s}$, and the time lag of relay is $0.05 \mathrm{~s}$. Simulation results are shown in Figure 3. It is clear that the stability of the guide vane opening is most affected because of the time delay of the relay. The deviation of the guide vane opening produces a large fluctuation at $0.05 \mathrm{~s}$. Then, an attenuated oscillation with a period of $0.05 \mathrm{~s}$ is generated. Due to the coupling effect of the system, the angle of the generator rotor angle deviation, the rotational speed relative deviation of the generator, and the hydro-turbine output incremental torque deviation have been affected to varying degrees, respectively. Under the action of the controller, the deviation of the guide vane opening achieves normal operation range after $0.3 \mathrm{~s}$. The angle of the generator rotor angle deviation achieves normal operation range after $0.1 \mathrm{~s}$. The rotational speed relative deviation of the generator and the hydro-turbine output incremental torque deviation achieve normal operation range after $0.1 \mathrm{~s}$. In addition, we can find that the largest vibration amplitude is the angle of generator rotor angle deviation (0.267), followed by the hydro-turbine output incremental torque deviation (0.027), the rotational speed relative deviation of the generator (0.025) and the deviation of the guide vane opening $(0.015)$. 
Overall, the state variables of the hydraulic turbine governing system tend to be stable, which verifies the effectiveness of the proposed controller. The state variables of the hydraulic turbine governing system are coupled with each other and all of the state variables reach stability after the same periodic attenuated oscillation. Considering the two factors of stabilization time and oscillation amplitude, we can obtain the ranking of the influence degree of relay delay on various variables of the system. The most sensitive is the deviation of the guide vane opening, followed by the angle of generator rotor angle deviation, the hydro-turbine output incremental torque deviation, and the rotational speed relative deviation of the generator.

\subsection{Case 2: Disturbance Analysis}

As an important index to measure power quality, there is a high requirement for frequency in hydropower station operation. The frequency of a hydropower station is related to the rotational speed of the hydro-generator unit. When the turbine torque and the generator load torque is equal, the unit speed will remain constant. However, when the load of the generator fluctuates, the hydro-generator unit operation will be affected. In China, the fluctuation range of electricity frequency is $\pm 0.2 \mathrm{~Hz}$. And in some cases, it can reach $\pm 1 \mathrm{~Hz}$. In this experiment, a positive perturbation of $2 \%$ rated speed was given as a step signal to excite the generator set at $t=0.3 \mathrm{~s}$. That is, the frequency reaches $51 \mathrm{~Hz}$.

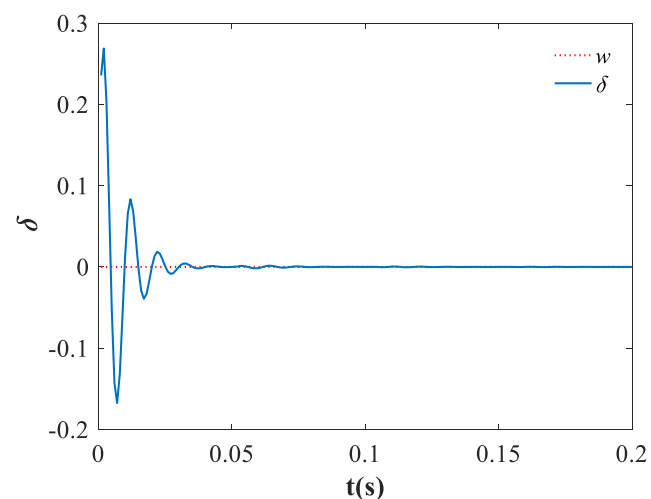

(a) $\delta(t)-t$

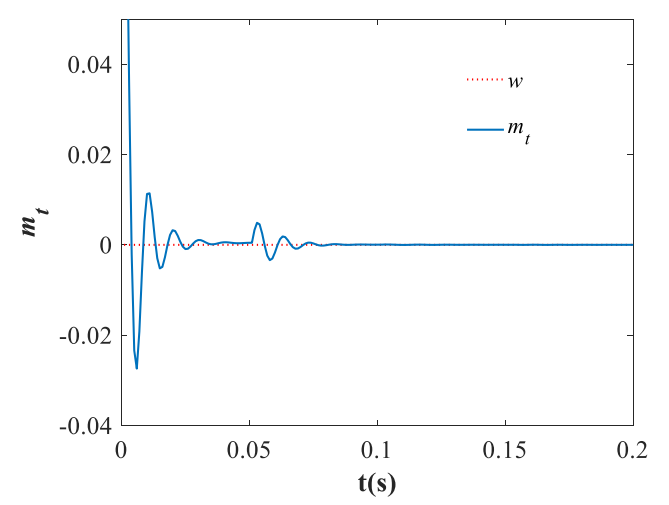

(c) $m_{t}(t)-t$

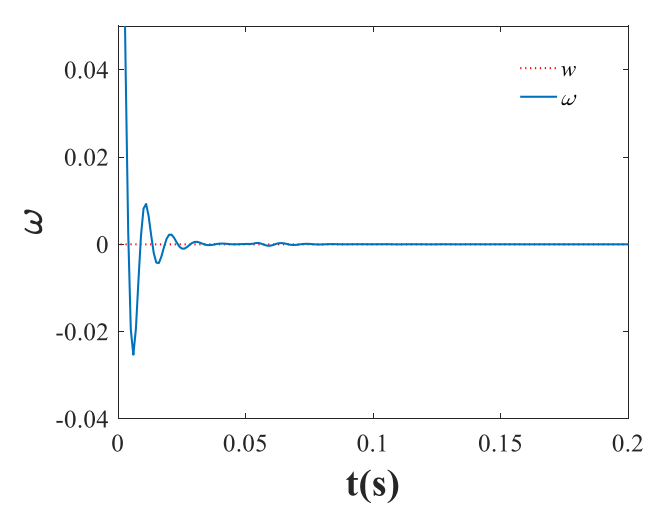

(b) $\omega(t)-t$

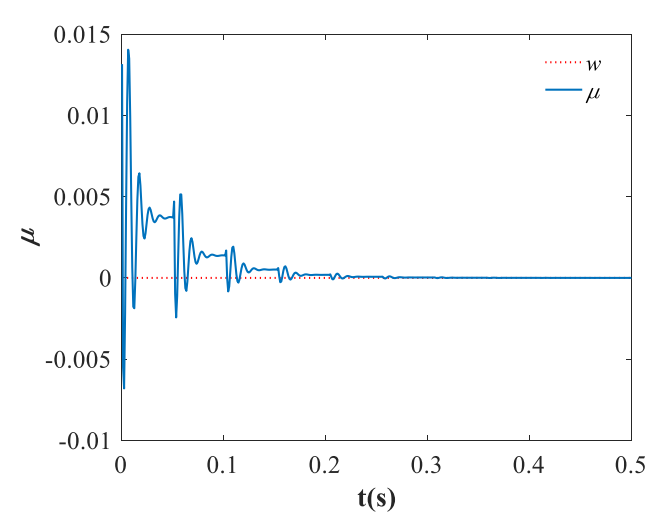

(d) $\mu(t)-t$

Figure 3. State responses of the fractional-order time-delay HTGS (3) under match model.

Experiment results are presented in Figure 4. When the speed of hydro-generator unit is affected by the grid load disturbance, clearly, the rotational speed relative deviation of the generator, the deviation of the guide vane opening, the angle of generator rotor angle deviation, and the hydro-turbine output incremental torque deviation all have a perturbation almost at the same time. We can see that the rotational speed relative deviation of the generator jumps to 0.02 at $0.3 \mathrm{~s}$, and it return to the normal speed quickly as well as the other state variables under the action of the proposed controller. 
That is, the frequency recovers to $50 \mathrm{~Hz}$. The control process is represented by local enlargement. Through the partial enlargement, the ranking of oscillation amplitude in the order from large to small is the rotational speed relative deviation of the generator, the deviation of the guide vane opening, the angle of generator rotor angle deviation, and the hydro-turbine output incremental torque deviation. The change of load has bigger influence on the rotating speed and the guide vane opening than angle of generator rotor angle and hydro-turbine output torque. Based on the experiment, it can be seen that the proposed nonlinear generalized predictive control (NGPC) has a desirable control performance under the rotational speed disturbance, which shows the robustness of the designed scheme.

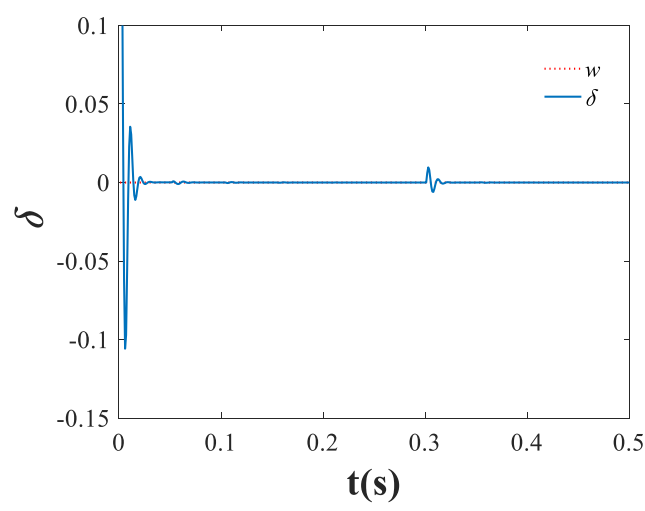

(a) $\delta(t)-t$

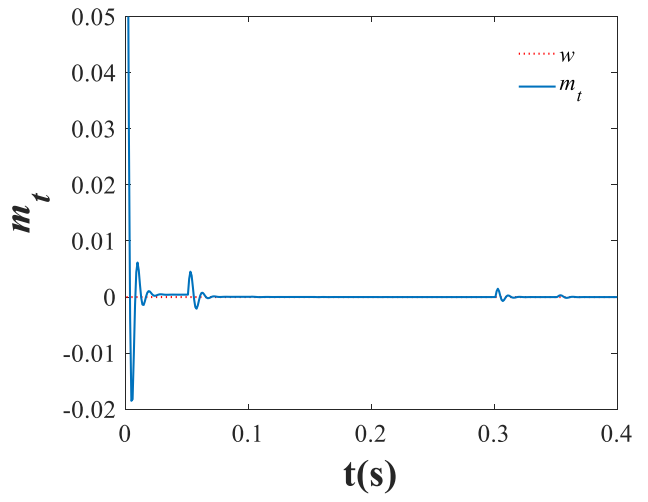

(c) $m_{t}(t)-t$

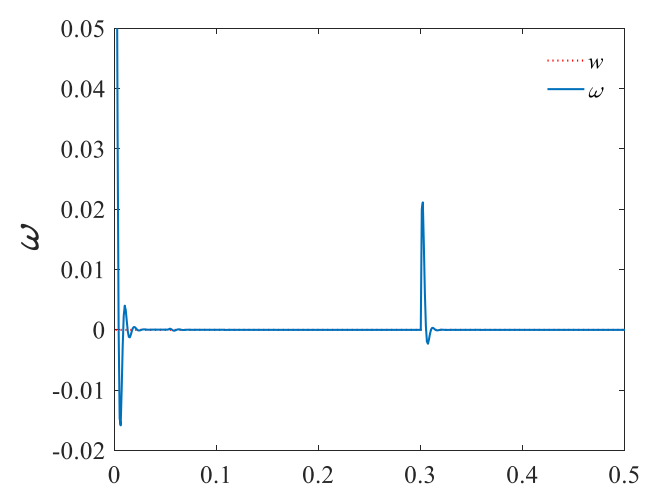

(b) $\omega(t)-t$

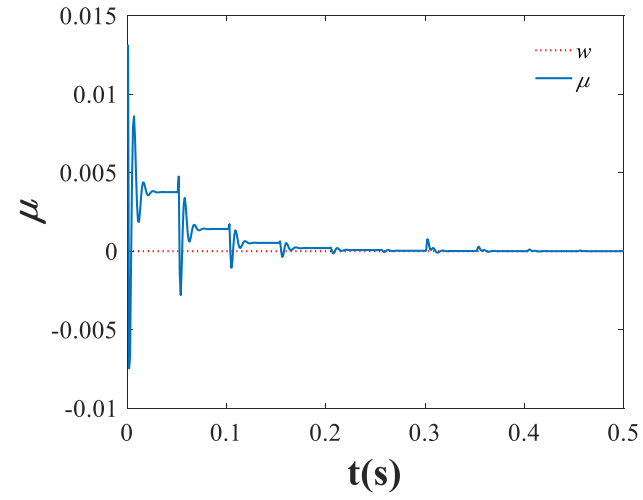

(d) $\mu(t)-t$

Figure 4. State responses of the fractional-order time-delay of the hydraulic turbine governing system (HTGS) (3) under step disturbances.

\subsection{Case 3: Effects of Time Delay}

The movable guide vane is a key mechanical component for the adjustment of unit capacity and frequency. When the unit capacity rises, the opening degree of movable guide vane will rise, and more water will pass through the turbine. In contrast, the opening degree will decrease. Therefore, the power quality is closely related to the precise control of the movable guide vane. However, when the relay operates, due to the mechanical inertia of the hydraulic component amplifier, the action of the movable guide vane will have a time lag. In this experiment, the influence of time delay term is explored.

The delay time of the relay is set as $0.05 \mathrm{~s}, 0.06 \mathrm{~s}, 0.08 \mathrm{~s}$, and $0.1 \mathrm{~s}$. Experiment results are shown in Figure 5. First, all the state variables can be stabilized under the proposed NGPC controller. By comparing the control performance of various variables, we can find that with the increase of time delay, the stabilization time as well as the amplitude also increases. The stabilization time of the guide vane opening is $0.3 \mathrm{~s}$ when the delay is $0.05 \mathrm{~s}$ and the stabilization time is $0.6 \mathrm{~s}$ when the time delay reaches $0.1 \mathrm{~s}$. In addition, when the time delays are $0.05 \mathrm{~s}, 0.06 \mathrm{~s}, 0.08 \mathrm{~s}$, and $0.1 \mathrm{~s}$, the attenuated oscillation periods are $0.05 \mathrm{~s}, 0.06 \mathrm{~s}, 0.08 \mathrm{~s}$, and $0.1 \mathrm{~s}$, respectively. Through the comparison of the time 
delay with the attenuated oscillation period, we can infer that the time delay may cause the attenuated oscillation. To sum up, it can be seen that the NGPC controller has a desirable control performance under different time delays, which verifies the effectiveness of the proposed NGPC method.

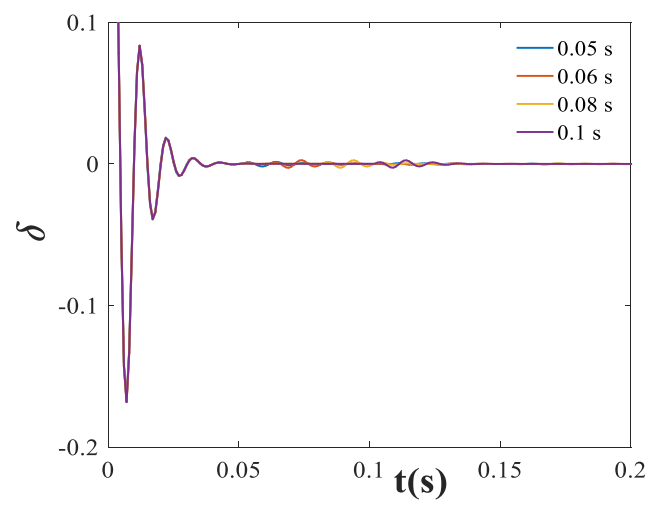

(a) $\delta(t)-t$

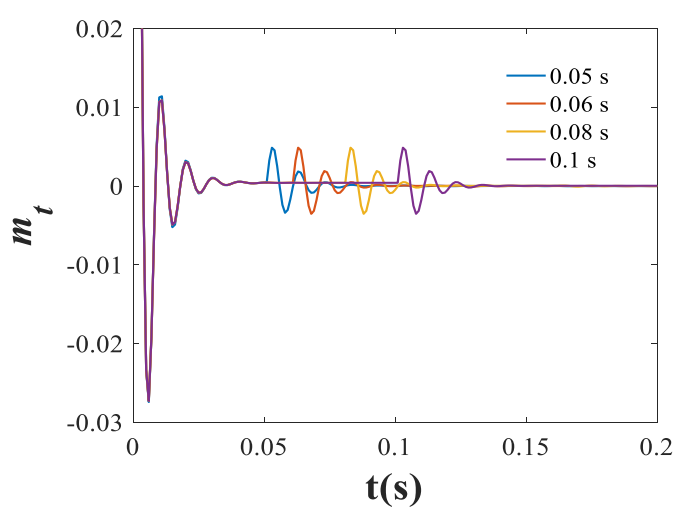

(c) $m_{t}(t)-t$

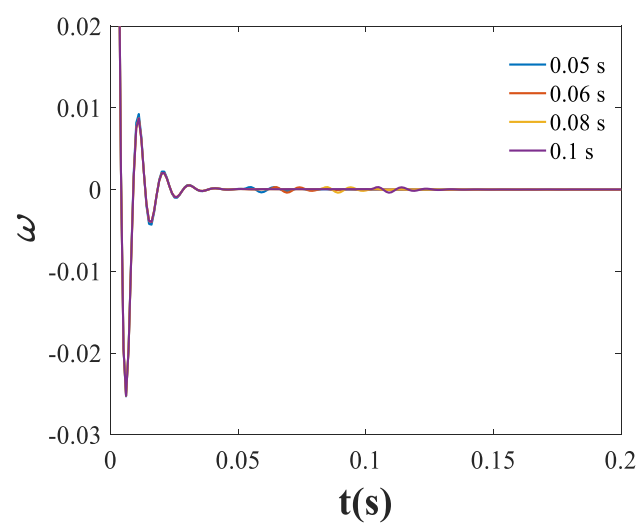

(b) $\omega(t)-t$

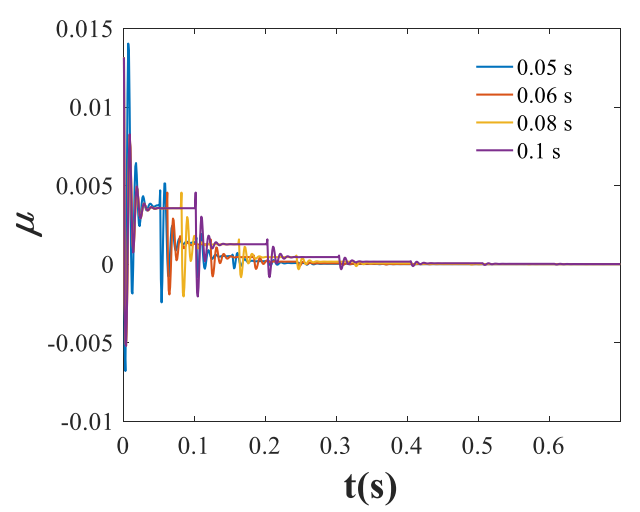

(d) $\mu(t)-t$

Figure 5. State responses of the fractional-order time-delay HTGS (3) under different time-delay steps.

\section{Conclusions and Discussion}

A nonlinear generalized predictive control was proposed to stabilize a fractional-order HTGS with a time delay in this study. A fractional-order HTGS model that was more in line with engineering practice was presented. Then, based on the transformed overall CARMA model and GPC theory, a novel nonlinear predictive control was designed for the fractional-order time-delay HTGS. Considering model match and load disturbance, numerical experiments of the fractional-order nonlinear HTGS with a time delay were carried out. The NGPC controller proposed in this paper could achieve the desired control performance, which verified the effectiveness and robustness of the proposed controller. From the experiment of the fractional-order HTGS with different time delays, we found that the time delay of the relay had an impact on the hydro-generating units. The control of the HTGS became more difficult as the time delay increased.

At the same time, the study also has some shortcomings. As the amount of control needs to be calculated online, a higher speed of hardware processing is required. Although the time delay of the relay is considered in this paper, the delay is small. Future work is to study the control of the HTGS with a large delay.

Author Contributions: Conceptualization, Y.T. and B.W.; methodology, Y.T.; software, S.W.; validation, Y.T., P.C. and Y.Y.; formal analysis, B.W.; investigation, Y.T.; resources, Y.T.; data curation, Y.Y.; writing-original draft preparation, Y.T.; writing - review and editing, B. Wang and D.C.; visualization, B.W.; supervision, D.C.; project administration, B.W.; funding acquisition, B.W. and D.C. 
Funding: This research was funded by National Natural Science Foundation of China, grant number 51509210; Shaanxi Province Science and Technology Plan, grant number 2016KTZDNY-01-01; Science and Technology Project of Shaanxi Provincial Water Resources Department, grant number 2017slkj-2 and Young Scholar Project of Cyrus Tang Foundation.

Conflicts of Interest: The authors declare that there is no conflict of interests regarding the publication of this paper.

\section{References}

1. Guerrier, G.; Paul, R.; Sananikhom, P.; Kaul, S.; Luthi, R.; Katz, J.P.; Robino, M.; Khammanithong, P.; Brey, P.T. Strategic success for hydropower in Laos. Science 2011, 334, 38. [CrossRef] [PubMed]

2. Li, X.Z.; Chen, Z.J.; Fan, X.C.; Cheng, Z.J. Hydropower development situation and prospects in China. Renew. Sustain. Energy Rev. 2017, 82, 232-239. [CrossRef]

3. Tsai, Y.C.; Chan, Y.K.; Ko, F.K.; Yang, J.T. Integrated operation of renewable energy sources and water resources. Energy Convers. Manag. 2018, 160, 439-454. [CrossRef]

4. Johan, B.; Per, S.; Urban, L. Torsional stability of hydropower units under influence of subsynchronous oscillations. IEEE Trans. Power Syst. 2013, 28, 3826-3833.

5. Yang, W.J.; Per, N.; Chung, C.Y.; Yang, J.D.; Lundin, U. Eigen-analysis of hydraulic-mechanical-electrical coupling mechanism for small signal stability of hydropower plant. Renew. Energy 2018, 115, 1014-1025. [CrossRef]

6. Yang, W.J.; Norrlund, P.; Saarinen, L.; Witt, A.; Simith, B.; Yang, J.D.; Lundin, U. Burden on hydropower units for short-term balancing of renewable power systems. Nat. Commun. 2018, 9, 2633. [CrossRef] [PubMed]

7. Vereide, K.; Svingen, B.; Nielsen, T.K.; Lia, L. The effect of surge tank throttling on governor stability, power control, and hydraulic transients in hydropower plants. IEEE Trans. Energy Convers. 2017, 32, 91-98. [CrossRef]

8. Qian, J.; Zeng, Y.; Guo, Y.K.; Zhang, L.X. Reconstruction of the complete characteristics of the hydro turbine based on inner energy loss. Nonlinear Dyn. 2016, 86, 963-973. [CrossRef]

9. Yu, X.D.; Zhang, J.; Fan, C.Y.; Chen, S. Stability analysis of governor-turbine-hydraulic system by state space method and graph theory. Energy 2016, 114, 613-622. [CrossRef]

10. Guo, W.C.; Yang, J.D. Modeling and dynamic response control for primary frequency regulation of hydro-turbine governing system with surge tank. Renew. Energy 2018, 121, 173-187. [CrossRef]

11. Guo, W.C.; Yang, J.D. Dynamic performance analysis of hydro-turbine governing system considering combined effect of downstream surge tank and sloping ceiling tailrace tunnel. Renew. Energy 2018, 129, 638-651. [CrossRef]

12. Xu, B.B.; Chen, D.Y.; Venkateshkumar, M.; Xiao, Y.; Yue, Y.; Xing, Y.Q.; Li, P.Q. Modeling a pumped storage hydropower integrated to a hybrid power system with solar-wind power and its stability analysis. Appl. Energy 2019, 248, 446-462. [CrossRef]

13. Xu, B.B.; Chen, D.Y.; Patelli, E.; Shen, H.J.; Park, J.H. Mathematical model and parametric uncertainty analysis of a hydraulic generating system. Renew. Energy 2019, 136, 1217-1230. [CrossRef]

14. Li, C.S.; Zou, W.; Zhang, N.; Lai, X.J. An evolving T-S fuzzy model identification approach based on a special membership function and its application on pump-turbine governing system. Eng. Appl. Artif. Intell. 2018, 69, 93-103. [CrossRef]

15. Zhang, Y.N.; Zheng, X.H.; Li, J.W.; Du, X.Z. Experimental study on the vibrational performance and its physical origins of a prototype reversible pump turbine in the pumped hydro energy storage power station. Renew. Energy 2019, 130, 667-676. [CrossRef]

16. Yan, D.L.; Wang, W.Y.; Chen, Q.J. Nonlinear modeling and dynamic analyses of the hydro-turbine governing system in the load shedding transient regime. Energies 2018, 11, 1244. [CrossRef]

17. Guo, W.C. A review of the hydraulic transient and dynamic behavior of hydropower plants with sloping ceiling tailrace tunnels. Energies 2019, 12, 3220. [CrossRef]

18. Long, Y.; Xu, B.B.; Chen, D.Y.; Ye, W. Dynamic characteristics for a hydro-turbine governing system with viscoelastic materials described by fractional calculus. Appl. Math. Model. 2018, 58, 128-139. [CrossRef]

19. Chen, K.; Tang, R.N.; Li, C.; Wei, P.N. Robust adaptive fractional-order observer for a class of fractional-order nonlinear systems with unknown parameters. Nonlinear Dyn. 2018, 94, 415-427. [CrossRef] 
20. Chen, Z.H.; Yuan, X.H.; Ji, B.; Wang, P.T.; Tian, H. Design of a fractional order PID controller for hydraulic turbine regulating system using chaotic non-dominated sorting genetic algorithm II. Energy Convers. Manag. 2014, 84, 390-404. [CrossRef]

21. Xu, Y.H.; Zhou, J.Z.; Xue, X.M.; Fu, W.L.; Zhu, W.L.; Li, C.S. An adaptively fast fuzzy fractional order PID control for pumped storage hydro unit using improved gravitational search algorithm. Energy Convers. Manag. 2016, 111, 67-78. [CrossRef]

22. Salahshour, S.; Ahmadian, A.; Senu, N.; Baleanu, D.; Agarwal, P. On Analytical Solutions of the Fractional Differential Equation with Uncertainty: Application to the Basset Problem. Entropy 2015, 17, 885-902. [CrossRef]

23. Agarwal, P. Further Results on Fractional Calculus of Saigo Operators. Appl. Appl. Math. 2012, 7, 585-594.

24. Agarwal, P.; Al-Mdallal, Q.; Cho, Y.J.; Jain, S. Fractional differential equations for the generalized Mittag-Leffler function. Adv. Differ. Equ. 2018, 58. [CrossRef]

25. Agarwal, P.; El-Sayed, A.A. Non-standard finite difference and Chebyshev collocation methods for solving fractional diffusion equation. Physica A 2018, 500, 40-49. [CrossRef]

26. Agarwal, P.; Nieto, J.J. Some fractional integral formulas for the Mittag-Leffler type function with four parameters. Open Math. 2015, 13, 537-546. [CrossRef]

27. Agarwal, P.; Jain, S.; Mansour, T. Further extended Caputo fractional derivative operator and its applications. Russ. J. Math. Phys. 2017, 24, 415-425. [CrossRef]

28. Baltaeva, U.; Agarwal, P. Boundary-value problems for the third-order loaded equation with noncharacteristic type-change boundaries. Math. Method. Appl. Sci. 2018, 41, 3307-3315. [CrossRef]

29. Ruzhansky, M.; Cho, Y.J.; Agarwal, P.; Area, I. Advances in Real and Complex Analysis with Applications; Springer Nature Singapore Pte Ltd.: Singapore, 2017; pp. 1-5.

30. Wang, F.F.; Chen, D.Y.; Xu, B.B.; Zhang, H. Nonlinear dynamics of a novel fractional-order Francis hydro-turbine governing system with time delay. Chaos Solitons Fractals 2016, 91, 329-338. [CrossRef]

31. Xu, B.B.; Chen, D.Y.; Zhang, H. Hamiltonian model and dynamic analyses for a hydro-turbine governing system with fractional item and time-lag. Commun. Nonlinear Sci. 2017, 47, 35-47. [CrossRef]

32. Huang, S.H.; Zhou, B.; Bu, S.Q.; Li, C.B.; Zhang, C.; Wang, H.Z.; Wang, T. Robust fixed-time sliding mode control for fractional-order nonlinear hydro-turbine governing system. Renew. Energy 2019, 139, 447-458. [CrossRef]

33. Guo, B.C.; Guo, J. Feedback linearization and reaching law based sliding mode control design for nonlinear hydraulic turbine governing system. Energies 2019, 12, 2273. [CrossRef]

34. Li, C.S.; Zhang, N.; Lai, X.J.; Zhou, J.Z.; Xu, Y.H. Design of a fractional-order PID controller for a pumped storage unit using a gravitational search algorithm based on the Cauchy and Gaussian mutation. Inform. Sci. 2017, 396, 162-181. [CrossRef]

35. Zhang, G.T.; Cheng, Y.C.; Lu, N.; Guo, Q. Research of hydro-turbine governor supplementary control strategy for islanding AC grid at sending terminal of HVDC system. IEEE Trans. Energy Convers. 2016, 31, 1229-1238. [CrossRef]

36. Liang, J.; Yuan, X.H.; Yuan, Y.B.; Chen, Z.H.; Li, Y.Z. Nonlinear dynamic analysis and robust controller design for Francis hydraulic turbine regulating system with a straight-tube surge tank. Mech. Syst. Signal Process. 2017, 85, 927-946. [CrossRef]

37. Jiang, C.W.; Ma, Y.C.; Wang, C.M. PID controller parameters optimization of hydro-turbine governing systems using deterministic-chaotic-mutation evolutionary programming (DCMEP). Energy Convers. Manag. 2016, 47, 1222-1230. [CrossRef]

38. Yang, W.J.; Norrlund, P.; Saarinen, L.; Yang, J.D.; Guo, W.; Zeng, W. Wear and tear on hydro power turbines-Influence from primary frequency control. Renew. Energy 2016, 87, 88-95. [CrossRef]

39. Wang, B.; Xue, J.Y.; Wu, F.J.; Zhu, D.L. Robust Takagi-Sugeno fuzzy control for fractional order hydro-turbine governing system. ISA Trans. 2016, 65, 72-80. [CrossRef]

40. Wang, B.; Xue, J.Y.; Wu, F.J.; Zhu, D.L. Finite time Takagi-Sugeno fuzzy control for hydro-turbine governing system. J. Vib. Control 2018, 24, 1001-1010. [CrossRef]

41. Muthukumar, P.; Balasubramaniam, P.; Ratnavelu, K. T-S fuzzy predictive control for fractional order dynamical systems and its applications. Nonlinear Dyn. 2016, 86, 751-763. [CrossRef]

42. Li, C.S.; Mao, Y.F.; Yang, J.D.; Wang, Z.B.; Xu, Y.H. A nonlinear generalized predictive control for pumped storage unit. Renew. Energy 2017, 114, 945-959. [CrossRef] 
43. Sala, A.; Hernandez-Mejias, M.; Arino, C. Stable receding-horizon scenario predictive control for Markov-jump linear systems. Automatica 2017, 86, 121-128. [CrossRef]

44. Teng, L.; Wang, Y.Y.; Cai, W.J.; Li, H. Fuzzy model predictive control of discrete-time systems with time-varying delay and disturbances. IEEE Trans. Fuzzy Syst. 2018, 26, 1192-1206. [CrossRef]

45. Ling, D.J. Bifurcation and Chaos of Hydraulic Turbine Governor; Nanjing Hohai University: Jiangsu, China, 2007.

46. Zhou, Y.; Wang, H.X.; Liu, H. Generalized Function Projective Synchronization of Incommensurate Fractional-Order Chaotic Systems with Inputs Saturation. Int. J. Fuzzy Syst. 2019, 21, 829-836. [CrossRef]

47. Zhang, D.; Jing, Y.W.; Zhang, Q.L.; Dimirovski, G.M. Stabilization of singular T-S fuzzy Markovian jump system with mode-dependent derivative-term coefficient via sliding mode control. Appl. Math. Comput. 2020, 364, 124643. [CrossRef]

48. Zhang, J.S.; Chen, W.H.; Lu, X.M. Robust fuzzy stabilization of nonlinear time-delay systems subject to impulsive perturbations. Commun. Nonlinear Sci. 2020, 80, 104953. [CrossRef]

(C) 2019 by the authors. Licensee MDPI, Basel, Switzerland. This article is an open access article distributed under the terms and conditions of the Creative Commons Attribution (CC BY) license (http://creativecommons.org/licenses/by/4.0/). 